HUOM! Tämä on alkuperäisen artikkelin rinnakkaistallenne. Rinnakkaistallenne saattaa erota alkuperäisestä sivutukseltaan ja painoasultaan.

Käytä viittauksessa alkuperäistä lähdettä:

R. Khan, J. Heikkila, S. Mubaraz, J. Luomakoski (2021) INNOVATION PROCESS IN BUSINESS IDEA GENERATION: A CASE OF AN ENTREPRENEURIAL HACKATHON, EDULEARN21 Proceedings, pp. 826-834. DOI: 10.21125/edulearn.2021.0225

PLEASE NOTE! This in an electronic self-archived version of the original article. This reprint may differ from the original in pagination and typographic detail.

Please cite the original version:

R. Khan, J. Heikkila, S. Mubaraz, J. Luomakoski (2021) INNOVATION PROCESS IN BUSINESS IDEA GENERATION: A CASE OF AN ENTREPRENEURIAL HACKATHON, EDULEARN21 Proceedings, pp. 826-834. DOI: 10.21125/edulearn.2021.0225

All rights reserved. Copyright (C) 2021, IATED Academy 


\title{
INNOVATION PROCESS IN BUSINESS IDEA GENERATION: A CASE OF AN ENTREPRENEURIAL HACKATHON
}

\author{
R. Khan, J. Heikkilä, S. Mubaraz, J. Luomakoski \\ Haaga-Helia University of Applied Sciences (FINLAND)
}

\begin{abstract}
The entrepreneurial hackathons are suggested to be pedagogical innovations in entrepreneurial education. Students actively engage in an innovation process while generating business ideas. This paper seeks to study the innovation process during a hybrid entrepreneurial hackathon, a combination of both face-to-face and virtual learning platforms. International students from a Finnish higher educational institute participated in this event. In order to get a clearer understanding of the innovation process of business idea generation, three stages are explored during the hybrid hackathon: idea generation and identification, concept development, and concept evaluation and selection. This study follows a quantitative research methodology. The empirical data was collected through two surveys: the first one was given to the students in the beginning of the three-day hackathon and the second one at the end of the hackathon. Our analysis shows that according to the participants, external idea sources are as important as the internal idea sources and open innovation is the way to understand innovation. In addition, while determining the team approach, the participants assessed their approach as more conventional than out-of-the-box and somewhere between problem and solution centric. Furthermore, the participants were able to collect relevant information, assess the feasibility of their business ideas and were able to screen the best idea based on benefits and risks. This study contributes in providing insights into the innovation process and students' approach to business idea generation during an entrepreneurial hybrid hackathon.
\end{abstract}

Keywords: innovation process, business idea generation, hybrid hackathon, entrepreneurial hackathon, entrepreneurial education.

\section{INTRODUCTION}

Innovation has been the focus of constant attention by both industry and academia. The term 'innovation' dates back to the beginning of $20^{\text {th }}$ century where it was studied through the theory of economic development of Schumpeter. The author defined innovation as a 'new combination of existing resources, materials, or means of production' [1]. Schumpeter examined innovation as an economic concept that not only benefits the company that has created it, but also promotes the development of the whole economy through diffusion [1]. Drucker [2] noted that 'innovation is the tool of entrepreneurs, the means by which they exploit change as an opportunity for a new business or service'. Tidd et al. [3] defined innovation as 'the process of turning opportunity into new ideas and of putting these ideas into a widely used practice'. The contemporary approach to innovation, also known as open innovation, proposed by Chesbrough [4], unlinks the interdependence of innovation from its domestic environment. Chesbrough noted that innovation is 'a way to promote ideas, thoughts, processes and research in order to improve product development, provide better services to customers, increase efficiency and enhance the value added from external partnerships' [4]. Open innovation fosters the importance of opening up the innovation process by combining the exploration activities performed outside the firms' boundaries with in-house research and development (R\&D) activities [5]. Berkhout et al. [6] presented a cyclic innovation model and suggested that 'innovation may start anywhere and previous innovations inspire new ones: innovations build on innovation'.

Innovation implies varying degrees of newness or innovativeness, which indicates the importance of understanding different types of innovations. Innovation literature often classifies innovation in terms of product, process, service and organisational innovations. Innovation is also differentiated between radical and incremental according to its innovativeness. Radical innovation involves significant improvement in performance, which is the result of a major breakthrough or an application of a new technology while the incremental innovations involve modest improvements or simple adjustments to an existing product, process or service, which improves its competitive position [7]. Incremental innovations are more frequent than other types of innovation. 
In this study, we view innovation as a process. Process innovation [7] refers to new and significantly improved production or delivery method. The innovation process is composed of ideation phase, development phase and commercial phase [8]. According to Schumpeter [1], innovation process contains three stages: invention (idea generation), innovation (commercial exploration), diffusion (spread in the market). Kotsemir and Meissner [9] posit that innovation process model suggests three basic stages: ideation (generating/searching/selecting ideas for potential new products/processes), development (turning selected ideas into tangible/intangible product/process), and commercialisation (also termed as implementation/launch). According to Li [10], ideation sets the starting point of the innovation process, transforming new opportunities into concrete ideas. Innovation happens through individual learning and group discussion. The selected ideas end up being developed rapidly as the idea development progresses in an informal way by experienced experts instead of formal research and development projects. The concept development is done best by studying the issue from the perspective of the business model theory prepared by Osterwalder and Pigneur [11], who developed the Business Model Canvas tool with nine dimensions that cover the three conceptual pillars: a) creation of value (key partners, key activities, and key features); b) delivery of value (channels, customer segment, and customer relationships); and c) capture of value (cost structure and revenue structure).

Sustainable business idea generation is a challenging innovation task that can be accomplished by high functioning teams. Girotra et al. [12] examine the effectiveness of groups for idea generation and found out that hybrid groups are able to generate more ideas, better ideas, and discern the quality of the ideas they generate. Bjork and Magnusson [13] suggest that in order to increase the number of high-quality innovation ideas created by individuals, the possibility to interact with other people should be supported and facilitated. Furthermore, creative pedagogical innovations have been highly recommended in entrepreneurship studies by the experts. Olokundun et al. [14] posit that creative business idea generation is possible due to well-designed entrepreneurship programs. Another important aspect in business idea generation that is discussed widely by the academics is creativity [15], and creative behavior can be enhanced by innovative entrepreneurial pedagogies. Research has shown that visual templates also enhance team collaboration in innovation activities and can have the power to shape teamwork for innovation tasks [16].

Additionally, research confirms that the higher education institutions play a positive role in fostering the entrepreneurial capabilities of the students [17]. Recent studies have shown that novel learning methods that the institutions employ, for instance, entrepreneurial hackathons increase the entrepreneurial competencies of university graduates [18], [19]. Hybrid entrepreneurial hackathons that are combinations of face-to-face and virtual learning platforms could also offer new perspectives to the participants and enhance the entrepreneurial learning abilities of students. This study presents one such hybrid hackathon, where the participants develop sustainable business ideas, while working in teams. There is a need to understand the strong innovation process behind the development of business idea generation during the hybrid hackathon. After all, developing successful business ideas require creativity and communication among the participants [20], and exploring this process can offer novel viewpoints and increase our understanding of the phenomenon.

This paper investigates the innovation process in business idea generation during a hybrid entrepreneurial hackathon where the participants actively engage in the innovation process while generating sustainable business ideas. International students from a Finnish higher educational institution, who form the participant group, participate in this innovation process and create innovative business ideas during the hackathon. In order to get a clearer understanding of the innovation process of business idea generation, three stages are explored during the hybrid hackathon: idea generation and identification, concept development, and concept evaluation and selection. The commercialisation stage is not applicable to our study as the ideas were not implemented into actual businesses during the hackathon. The remaining sections of the study discuss the methods, followed by the empirical results and conclusion.

\section{METHODOLOGY}

\subsection{Hybrid Hackathon}

This study focusses on the innovation process as part of the business idea generation in a hybrid event involving international students. The data for this study is collected during a hybrid entrepreneurial hackathon, which was arranged during COVID-19 pandemic. The hackathon was a three-day hybrid event consisting of both online and onsite activities. Event was organised where international students 
were engaged in innovation process to generate innovative business ideas while working in teams. Unlike pure online event, this hybrid format of event supported an improved level of student engagement and better interaction among team members as well as mentors.

The main objective of the hybrid hackathon was to engage multidisciplinary student teams in innovative process to generate novel business ideas. The ideas were later presented by the teams at the end of the hackathon. The three-day hybrid entrepreneurial hackathon was arranged in September, 2020. The first day of the hackathon was organised as a face-to-face event at a suitable location in Helsinki, Finland. The following two days were organised virtually using suitable online learning platforms. Ninety students enrolled in the hybrid event. These students were supervised by eight mentors. On the first day, thirty-one students and seven mentors gathered physically onsite. As the event was also streamed live, other sixteen students and one mentor participated in the event remotely using the online learning platform. Thirty-seven students participated online while working in their respective multidisciplinary student teams. All eight coaches were also mentoring the students virtually. A total of thirty-seven male and female undergraduate students completed the course. The sample of this study is formed by the students who completed the course.

The multidisciplinary student teams engaged in the innovation process and collaborated to create novel business ideas. These business ideas were virtually presented to mentors at the end of the hybrid event. All the eight mentors continuously guided the student teams during the three-day hackathon. The mentors supported the student learning during the hybrid event. The students were given few days to submit the survey forms and the last student submitted the forms five days after the deadline. Authors agreed to include all thirty-six completed survey forms in the analysis as part of this study.

\subsection{Quantitative study}

The research design of this study is based on the quantitative research methodology. Earlier studies see for example [21], utilised similar approach to explore students' self and peer assessment practices in hybrid hackathon context. The research design utilizes empirical data that was collected first at the beginning of the hybrid hackathon as well as at the end of the event to study the innovation process in business idea generation. The students were informed about the voluntary nature of their participation and the confidentiality of the collected data.

The questions in both the surveys were based on the literature review of the main research area. A total of thirty-seven students submitted the first survey; answering the questions about the innovation process in general. During the evaluation of the surveys, one form was excluded from the sample by authors as it did not follow the instructions of filling-in the information. The total number of accepted surveys was thirty-six.

The second survey was conducted at the end of the hybrid event. Students were asked to provide their opinions about i) idea generation and identification, ii) concept development, and iii) concept evaluation and selection. Each of these three sections has several questions related to the main sub-topics. A total of sixteen students submitted the survey. Authors evaluated the surveys and accepted all of them to be included in the analysis. The authors analysed the data with the help of IBM SPSS software. The empirical data was entered into IBM SPSS statistical tool for the analysis. The analysis methods applied were the Spearman's correlation coefficient and Mann Whitney U-test.

\section{RESULTS}

This research focuses on studying the innovation process, especially idea generation and identification, concept development, and concept selection and evaluation stages of an innovation process model during the hackathon. As discussed in the introduction section, innovation approaches have evolved from being closed to open, where the innovation process is opened up to include exploration activities outside of the firm's boundaries. In this context, the researchers were interested in investigating the participants' understanding of the innovation process. The empirical data was carefully analysed to explore their understanding.

In the beginning of the hackathon, the participants were asked a question regarding their opinions about the innovation process. The idea was to investigate their understanding of innovation process, and whether they viewed this process as more closed or open. The participants $(n=36)$ agreed that the innovation can come from multiple sources-customers, suppliers, public as well as employees. Moreover, they agreed that the external sources are as important as the internal idea sources. However, 
half of the respondents agreed and half disagreed with the statement 'innovation process in an independent process separate from the other processes in the organisation'. (Fig. 1).

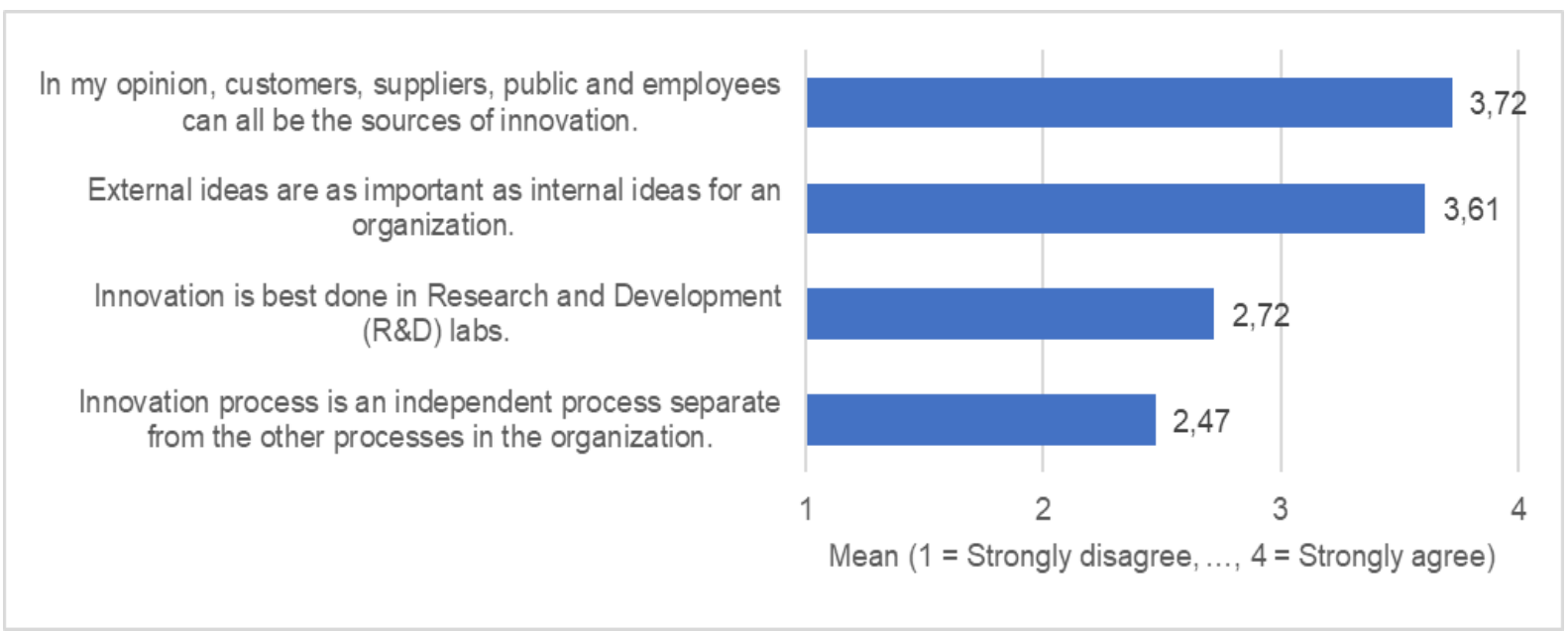

Figure 1. The respondents' opinions about innovation process prior to the hackathon

Similarly, the statement 'Innovation is best done in R\&D labs' divided the responses; $60 \%$ of the respondents agreed and $40 \%$ disagreed. However, the male respondents agreed more with statement compared to the female respondents (Fig. 2). The difference is statistically significant $(U=82.000, p=$ $0.019)$.

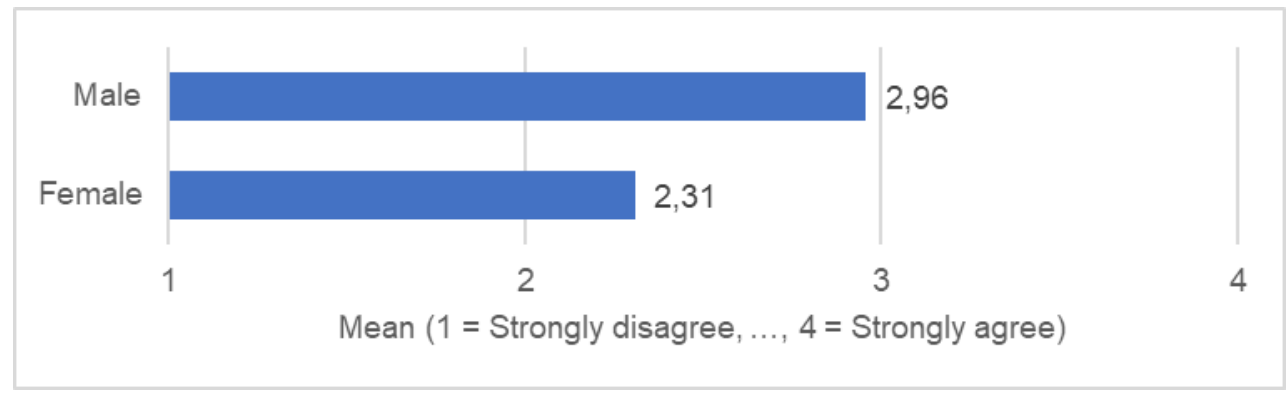

Figure 2. Agreement to statement 'Innovation is best done in R\&D labs' by gender

At the end of the three-day hackathon, the participants also participated in the second survey. Several issues were investigated under the main headings of the three stages of innovation process. First, idea generation process was investigated, where the participants were questioned about generation of ideas within their teams as well as their team's approach. Second, in the concept development stage, focus was on how the ideas were developed and refined and lastly, in the concept evaluation and selection stage, the team's ability to research and assess the feasibility of the business concept was investigated. The following paragraphs discuss the participants' responses at each stage.

\subsection{Idea generation and identification}

To get an insight about the idea generation and identification phase, the participants were asked about their team's idea generating capability. The students felt that they had discussed their ideas thoroughly, there was a free-flow of ideas and they were able to select their idea easily (Fig. 3). The participants $(n=16)$ faced no difficulties in generating and selecting the relevant ideas. 
The ideas were thoroughly discussed in the team.

There was a free-flow of ideas in our team.

We were able to select the relevant idea easily.
1

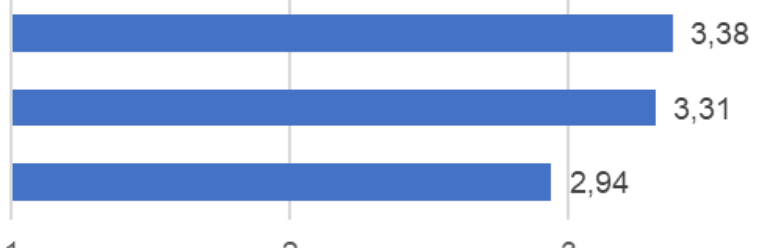

2

Mean $(1=$ Strongly disagree $, \ldots, 4=$ Strongly agree $)$

Figure 3. Agreement to statements about idea generation

Furthermore, the participants were also asked about their team approach. The researchers were interested to investigate whether the team used conventional mindset or out-of-the-box ideas. Moreover, the participants were asked whether their approach was problem-centric, where they identified the challenges first or solution centric, where they developed potential solutions. None of the students assessed their approach to be fully conventional, however, the overall the approach was more conventional than out-ofthe-box. The ideas were more evenly distributed between problem and solution centric approaches. However, none of the teams considered their approach as fully problem-centric. (Fig. 4)

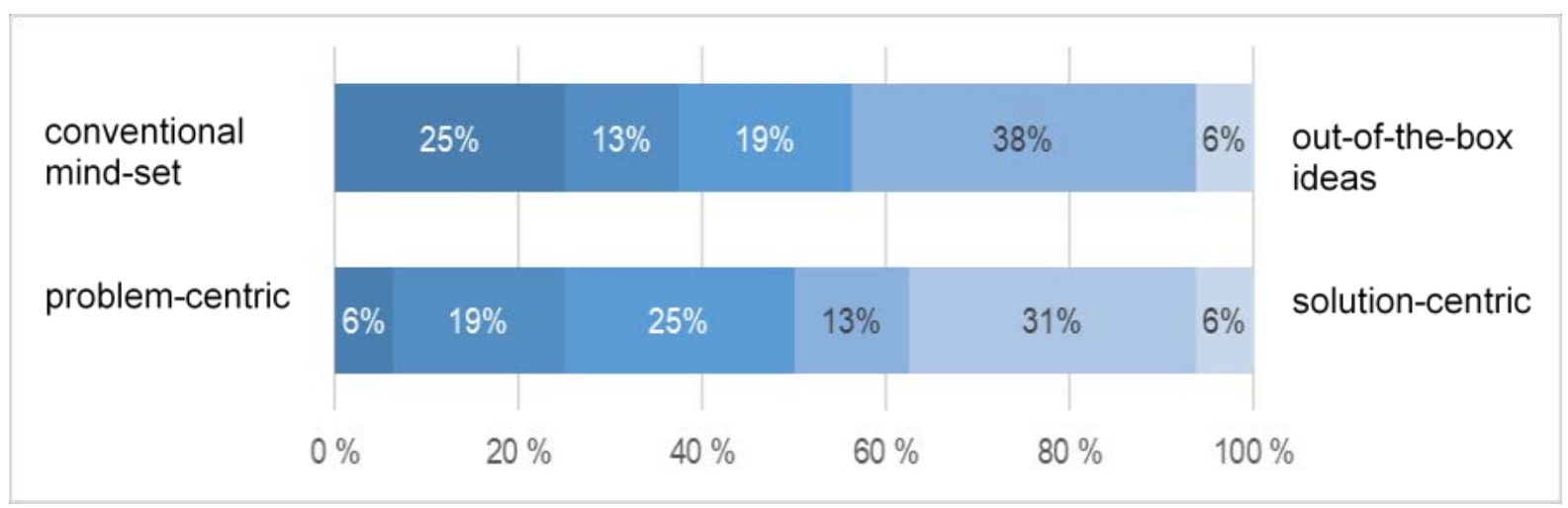

Figure 4. The students' approach in the idea generation stage of the innovation process

In addition to the team approach, the participants were also asked about the amount of ideas that were developed within their teams. Majority of the teams generated one to three ideas. However, a quarter of the teams generated four or more ideas. (Fig. 5).

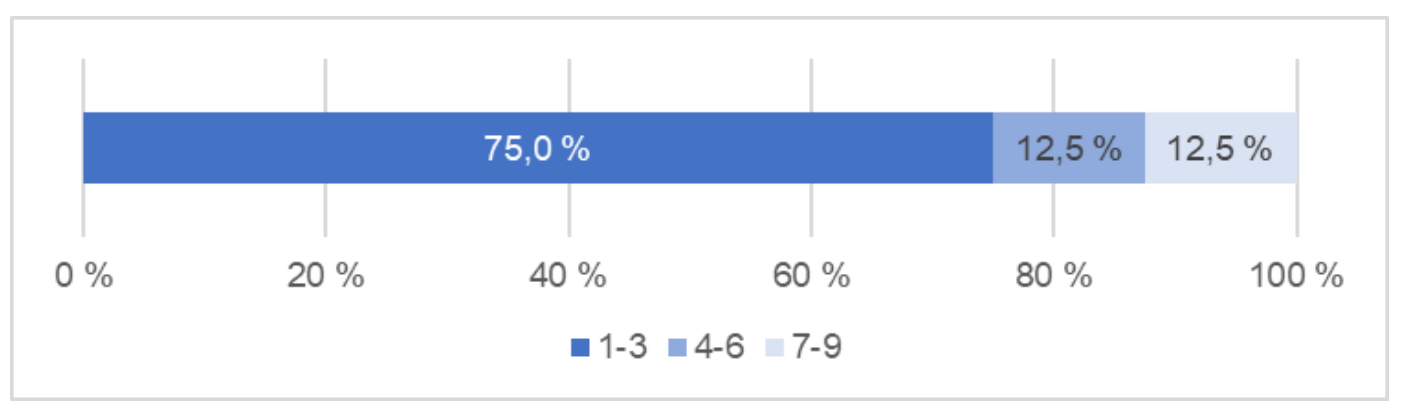

Figure 5. The number of business ideas the team developed

\subsection{Concept development}

For the concept development stage, the participants were asked about how their ideas were developed and refined. First of all, the teams were asked about how they selected their ideas and whether or not they were a combination of several ideas. Majority of the teams chose an idea presented by one team member. Only $13 \%$ of the teams were able to combine several team members' idea in the concept development stage. (Fig. 6) 


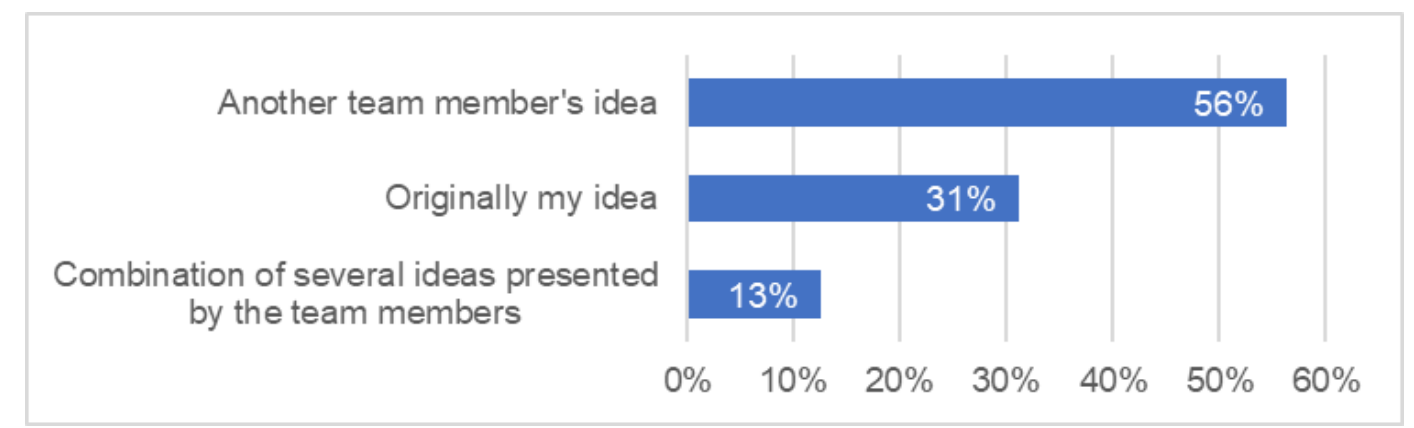

Figure 6. The idea chosen by the team

Next, the participants were asked about their idea selection and its duration. The time the teams used to formulate their ideas varied from less than 15 minutes to over an hour (Fig. 7). Some teams took more time while others were faster in their idea selection process.

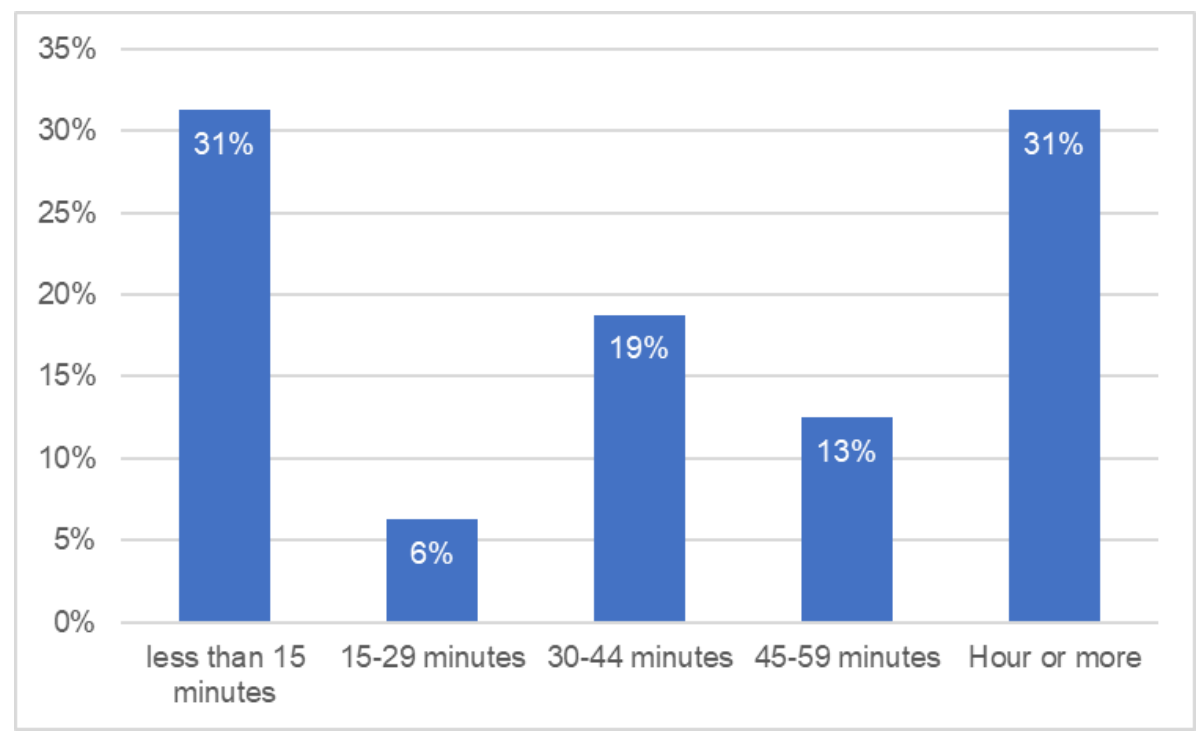

Figure 7. The time team has spent on idea formulation

\subsection{Concept evaluation and selection}

In the concept evaluation and selection stage, the team's ability to research and assess the feasibility of the business concept was investigated. The more time the students spent on the idea formulation, the more they agreed with the statement, 'The best concepts were screened after measuring the benefits and risks of the ideas.' $(r=0.568, p=0.022$, Table 1, Fig. 8).

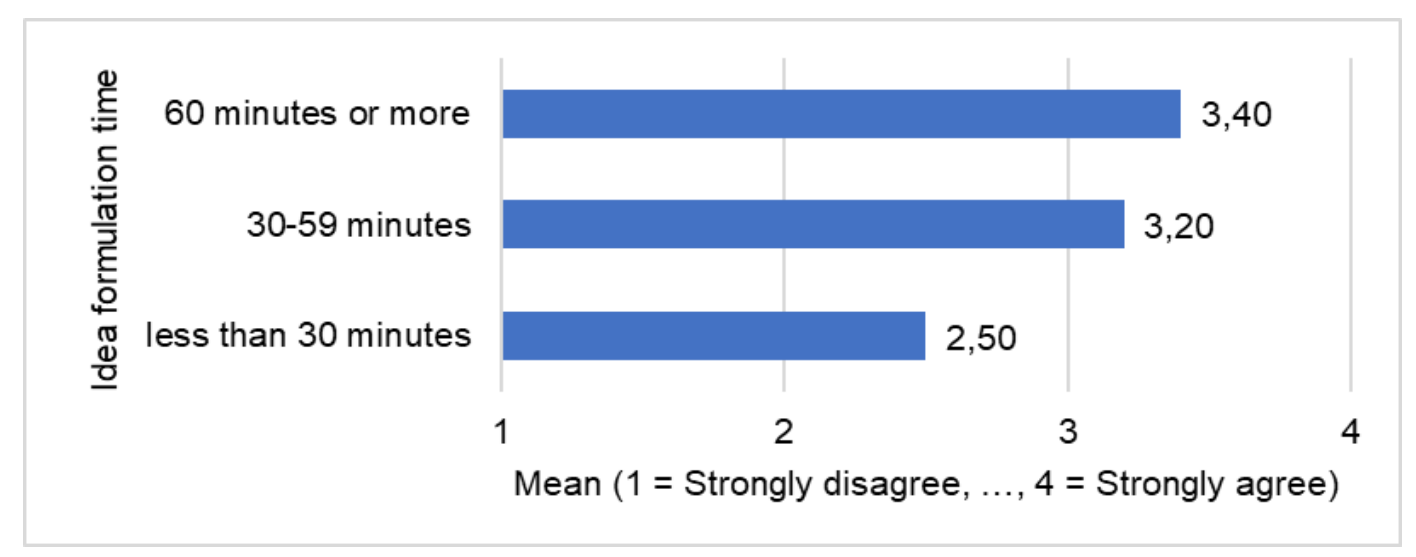

Figure 8. Agreement to screening the best concepts based on risks and benefits of the idea 
Table 1. The Spearman's correlation coefficient

\begin{tabular}{llc}
\hline & & $\begin{array}{c}\text { The best concepts were screened after } \\
\text { measuring the benefits and risks of the ideas. }\end{array}$ \\
\hline Time spent on & Correlation Coefficient & 0,568 \\
idea formulation & Sig. (2-tailed) & 0,022 \\
& $\mathrm{~N}$ & 16 \\
\hline
\end{tabular}

Furthermore, the participants were able to collect relevant information, assess the feasibility of their business concept as well as consider each student's opinion. Additionally, the students somewhat agreed that they have screened the best idea based on benefits and risks. About $75 \%$ of the students agreed, either somewhat or strongly that their business concept was chosen due to its futuristic approach. However, $25 \%$ of teams disagreed. (Fig. 9)

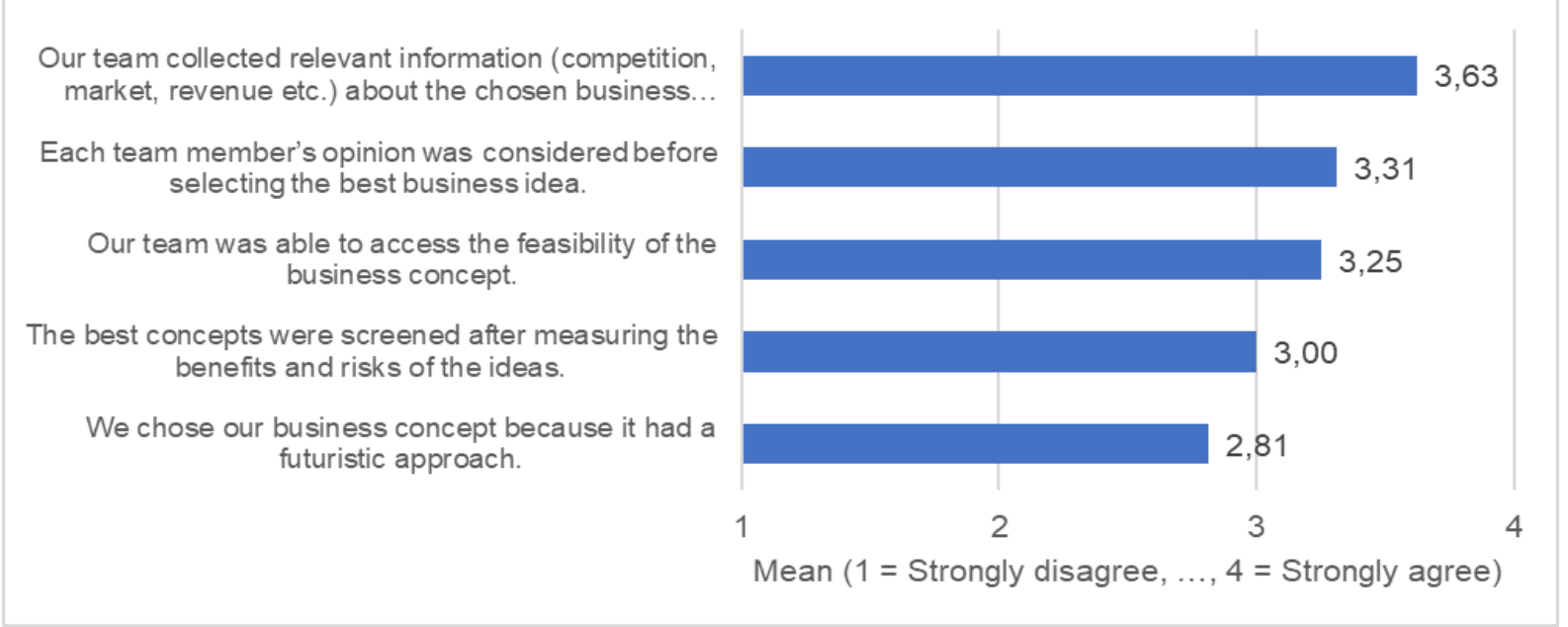

Figure 9. Agreement to statements about concept evaluation and selection ( $n=16)$

\section{CONCLUSIONS}

The context of this study is an entrepreneurial hackathon, which saw the participation of international students from a Finnish higher education institution. The hackathon was arranged in a hybrid format, where the students had the opportunity to participate either physically or virtually on the first day of the event. The rest of the days were arranged only in virtual format. The aim of the hackathon was the generation of novel business ideas. This study focuses on the innovation process of business idea generation.

The results show that the purpose of the hackathon is served as there was a free flow of ideas, which were thoroughly discussed within the teams during the event. Apparently, this eased the ability to select the idea to be developed further. The students viewed their ideas to be more conventional than out-ofthe-box and half of them perceived the ideas to be problem-centric and the other half as solution-centric. This can indicate that the idea generation in such a short time is done easier from conventional perspective than to create totally out-of-the-box ideas. In addition, a large majority of the teams developed only less than three ideas, only $25 \%$ of the teams created more than three ideas. A statistically significant difference was found between male and female students in response to the statement, 'Innovation is best done in R\&D labs' where male students agreed more with this statement. Overall, the majority of the students agreed with the aforementioned statement indicating that they were perhaps not fully aware of the open innovation concept.

The absolute majority of the teams created the concept based on one team member's idea. Only $13 \%$ of the teams managed to combine more than one idea to be developed further. About one-third of the teams managed to select the idea in less than 15 minutes and an equal number of teams spent more than an hour for the same process. Our study indicates that the more time the students spent on the idea formulation, the more time they spent on analysing the risks and benefits of the ideas. In addition, 
the teams collected relevant information about the chosen business as well as considered all team members' opinions before selecting the best idea.

Overall, the study indicates that the hackathon has met its goals by activating the students to freely create new business ideas, although more conventional than novel ones. In addition, the student teams that took time to create an idea also analysed the concept properly. This study has limitations; for example, the response rate was small. Therefore, the results cannot be generalized. We suggest that further studies should be conducted in this area with larger respondent groups.

\section{ACKNOWLEDGEMENTS}

The authors would like to express their gratitude to EU Interreg Central Baltic funded project NOCCA (Novel Opportunities for new Company Creation and Accelerated growth) for providing the valuable research material and opportunity to conduct the research.

\section{REFERENCES}

[1] J. A. Schumpeter, The theory of economic development: An inquiry into profits, capital, credit, interest, and the business cycle, New Jersey: Transaction publishers, 1934.

[2] P.F. Drucker, "The discipline of innovation", Harvard Business Review, vol.76, pp.149-157, 1998.

[3] J. Tidd, J, and R. Bessant, Managing Innovation: Integrating Technological, Market and Organisational Change. Chichester: Wiley. 2005.

[4] H. W. Chesbrough, "The era of open innovation," MIT Sloan Management Review, vol. 44, no. 3, pp. 34-41, 2003.

[5] J. Hsuan, and V. Mahnke, "Outsourcing R\&D: a review, model, and research agenda". $R \& D$ Management, vol. 41, pp.1-7, 2011.

[6] G. Berkhout, D. Hartmann, and P. Trott, "Connecting technological capabilities with market needs using a cyclic innovation model", R\&D Management, vol. 40, no. 5, pp. 474-490, 2010.

[7] D. Smith, Exploring innovation, New York: McGraw-Hill Higher Education, 2010.

[8] R. Garcia, "Types of Innovation", Technology and Innovation Management. Wiley Encyclopedia of Management, vol. 13, 2015. https://doi.org/10.1002/9781118785317.weom130013

[9] M. N. Kotsemir, and D. Meissner, "Conceptualizing the innovation process- trends and outlook". Higher School of Economics Research Paper No. WP BPR, 10, 2013.

[10] X. Li, Innovation Process in Research and Development Service Firms: The Case of the UK, 2017.

[11] A. Osterwalder, and Y. Pigneur, Business model generation. New Jersey: John Wiley \& Sons, 2010.

[12] K. Girotra, C. Terwiesch, and K. T. Ulrich, "Idea Generation and the Quality of the Best Idea". Management Science, vol.56, no. 4, pp. 591-605, 2010.

[13] J. Björk, and M. Magnusson, "Where do good innovation ideas come from? Exploring the influence of network connectivity on innovation idea quality". Journal of Product Innovation Management, vol.26, no.6, pp. 662-670, 2009.

[14] M. A. Olokundun, C. L.Moses, O. O. Iyiola, S. A. Ibidunni, and A. B. Amaihian, "Perceptions of students on Entrepreneurship curriculum contents and open-mindedness: Implications for Business Idea Generation of Nigerian University Students. Academy of Entrepreneurship Journal, vol.23, no. 2, pp. 1-10, 2017.

[15] J. Heinonen, U. Hytti, and P. Stenholm, "The role of creativity in opportunity search and business idea creation". Education + Training, vol. 53, no.8/9, pp. 659-672, 2011.

[16] M. J. Eppler, F. Hoffmann, and S. Bresciani, "New Business Model through collaborative idea generation", International Journal of Innovation Management, vol. 15, no. 6, pp. 1323-1341, 2011.

[17] A. Fayolle and B. Gailly, "Using the Theory of Planned behaviour to Assess Entrepreneurship Teaching Programmes", Louvain School of Management. Center for Research in Change, Innovation and Strategy (CRECIS) Working Pape, 2005. Retrieved from URL: http://www.crecis.be. 
[18] E. Rasmussen, and R. Sørheim, "Action-based entrepreneurship education", Technovation, vol. 26, no. 2, pp. 185-194, 2006.

[19] R. Khan, S. Mubaraz, J. Luomakoski, and J. Heikkilä, "Students' Perception of Business Idea Generation: A Case of Entrepreneurial Hackathon," in Proceedings of $14^{\text {th }}$ International Technology, Education and Development Conference, March $2^{\text {nd }}-4^{\text {th }}$, pp. 1758-1764, 2020.

[20] S. Hougaard, The Business Idea. The Early Stages of Entrepreneurship. Heidelberg: Springer, 2005.

[21] S. Mubaraz, J. Heikkilä, and L. Bellotti, "Students' self and peer assessment practices: a case of hybrid entrepreneurial hackathon". In $15^{\text {th }}$ International Technology, Education and Development Conference. International Academy of Technology Education and Development, pp. 4619-4623, 2021. 